\title{
SISÄKKÄISJYVISTÄ ERI KAURALAJIKKEILLA JA NIIDEN VAIKUTUKSESTA SIEMENTAVARAN PUHTAUTEEN
}

\author{
MERI JOKELA \\ Valtion siementarkastuslaitos, Helsinki
}

Saapunut 8. 8. 1961

Irrallisten jyvien lisäksi tapaa hyvinkin lajitellussa siemenkaurassa useimmiten myös ns. sisäkkäisjyviä. Ne ovat jyviä, joissa tähkylän ulkojyvän ulkohelve osittain, joskus kokonaankin sulkee sisäänsä tähkylän toisen jyvän. Tällaisessa sisäkkäisjyvässä on useimmiten ulkojyvä tyhjä, ja sisäjyvä on kehittynyt normaalia sisä-

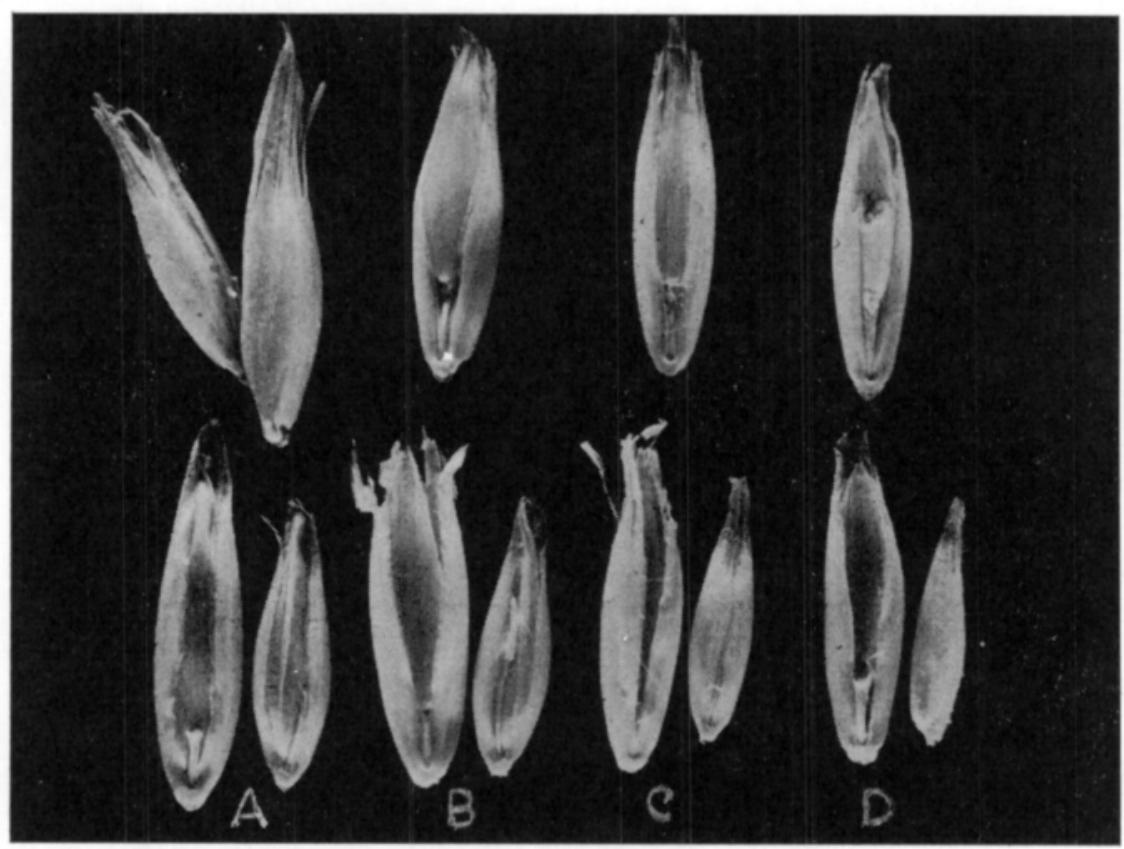

Kuva 1. Ylärivissä: A Normaali 2-jyväinen tähkylä, B sisäkkäisjyvä, jossa tyhjä ulkojyvä, C kaksonen, D sisäkkäisjyvä, jossa tyhjä sisäjyvä. - Alarivissä: Vastaavanlaisten tähkylöiden jyvät toisistaan irrotettuna.

Fig. 1. Above: A Normal spikelet with two grains, $B$ double grain with empty lower floret, $C$ double grain with two grains, D double grain with empty upper floret. - Below: Grains of similar spikelets separated from each other.

Foto O. Ulvinen. 
jyvää suuremmaksi. Toisinaan ovat molemmat jyvät kehittyneet, mutta ne ovat pienempiä kuin vastaavat normaalit jyvät. Joskus kehittynyt ulkojyvä sulkee sisäänsä melko suuren tyhjän sisäjyvän.

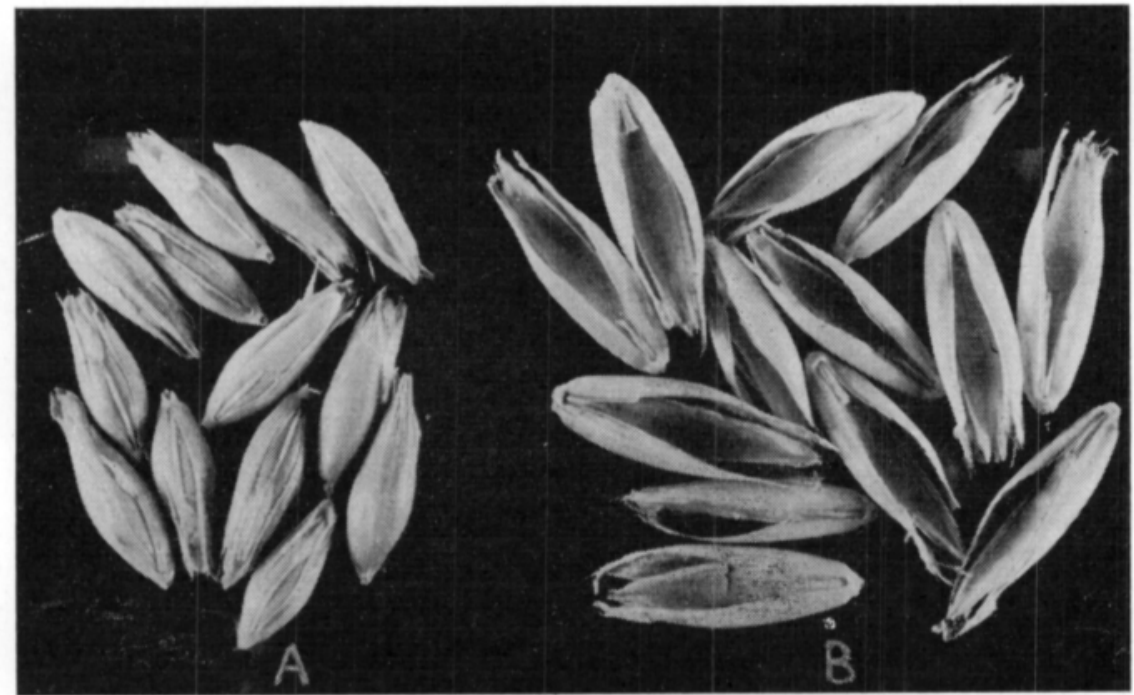

Kuva 2. Sisäkkäisjyvät, joissa tyhjä ulkojyvă, irrotettuna toisistaan, A jyviä, B tyhjiä ulkojyviä $=$ roskia.

Fig. 2. Double grains with empty lower floret separated from each other, $A$ grains, $B$ empty florets $=$ inert matter.

Foto O. Ulvinen.

Valtion siementarkastuslaitoksessa on aikaisemmin puhtausmäärityksen yhteydessa sisäkkäisjyvät irrotettu ja kumpikin jyvä arvosteltu erikseen. Lähinnä hitautensa vuoksi on tämä arvostelutapa nyt hylätty. Tarkastuskauden $1960-61$ alusta lähtien on sisäkkäisjyvät sellaisinaan katsottu puhtaiksi siemeniksi. Tässä siirtymävaiheessa on suoritettu tutkimuksia, joiden tarkoituksena on ollut selvitellä kauran sisäkkäisjyväkysymystä lähinnä siementavaran puhtauteen vaikuttavana tekijänä.

\section{Aineisto ja sen käsittely}

Tutkimus suoritettiin lajikkeittain, ja siihen sisältyivät kaikki meillä siemenkaupassa yleiset kauralajikkeet: Tammi, Kyrö, Pendek, Eho, Sisu, Orion III ja Nip. Kustakin lajikkeesta tutkittiin 55 eri siemenerää edustavaa näytettä sekä vuoden 1959 että vuoden 1960 sadosta. Näytteet otettiin umpimähkään niiden tarkastettavaksi lähetettyjen kauranäytteiden joukosta, joissa laboratoriossa tutkitun aitouden mukaan vieraita lajikkeita oli korkeintaan $2 \%$. Sisukaura-näytteistä on kuitenkin osa sellaisia, joissa lajike todettiin vain silmävaraisella yleistarkastuksella. Kustakin näytteestä otettiin $100 \mathrm{~g}: \mathrm{n}$ keskinäyte. Siitä erotettiin sisäkkäisjyvät, irrotettiin 
ne toisistaan sekä laskettiin eri tyyppisten sisäkkäisjyvien määrä. Sisäkkäisjyvistä irrotetut tyhjät helpeet punnittiin. Myös muut tässä 100 g:n näytteessä olevat roskat määritettiin.

\section{Sisäkkäisjyvien määrä eri lajikkeilla}

Tutkituilla lajikkeilla ilmeni sisäkkäisjyvien määrissä selviä eroja (taulukko, kuva 3). Nämä olivat samansuuntaisia molempina vuosina siitä huolimatta, että sisäkkäisjyviä v. 1959 sadossa oli kaikilla lajikkeilla enemmän kuin v. 1960 sadossa. Vaihtelut saman lajikkeen eri näytteiden välillä olivat suuret. Kaikista lajikkeista oli näytteitä, joissa sisäkkäisjyviä oli hyvin vähän.

Tutkituista lajikkeista oli eniten sisäkkäisjyviä Tammikauralla, v. 1959 keskim. $42.5 \mathrm{kpl} / 100 \mathrm{~g}$ ja v. 1960 keskim. $29.4 \mathrm{kpl} / 100 \mathrm{~g}$. Myös maksimimäärät olivat korkeimmat, v. 1959 jopa $145 \mathrm{kpl} / 100 \mathrm{~g}$. Eräässä saman vuoden satoa olevassa tähän aineistoon kuulumattomassa Tammikaura-näytteessä todettiin $100 \mathrm{~g}$ :ssa 170 sisäkkäisjyvää. Tammen sisäkkäisjyvistä oli noin neljäsosa kaksosia, siis sellaisia, joissa molemmat jyvät ovat kehittyneet. Runsaasti sisäkkäisjyviä sisältävä lajike oli myös Pendek. Sen sisäkkäisjyvistä oli kaksosia suhteellisesti vähemmän kuin muilla lajikkeilla. Nipkauralla oli sisäkkäisjyvien keskimäärä v. $195924.2 \mathrm{kpl} / 100 \mathrm{~g}$ ja v. $196014.7 \mathrm{kpl} / 100 \mathrm{~g}$. Kaksosten suhteellinen osuus sisäkkäisjyvistä oli Nipillä suurempi kuin millään muulla lajikkeella. Kyrökauralla oli sisäkkäisjyvien määrä kumpanakin vuonna samaa suuruusluokkaa kuin Nipillä, mutta kaksosten suhteellinen osuus oli pienempi. Maksimiarvot olivat Kyröllä keskimäärään verrattuna

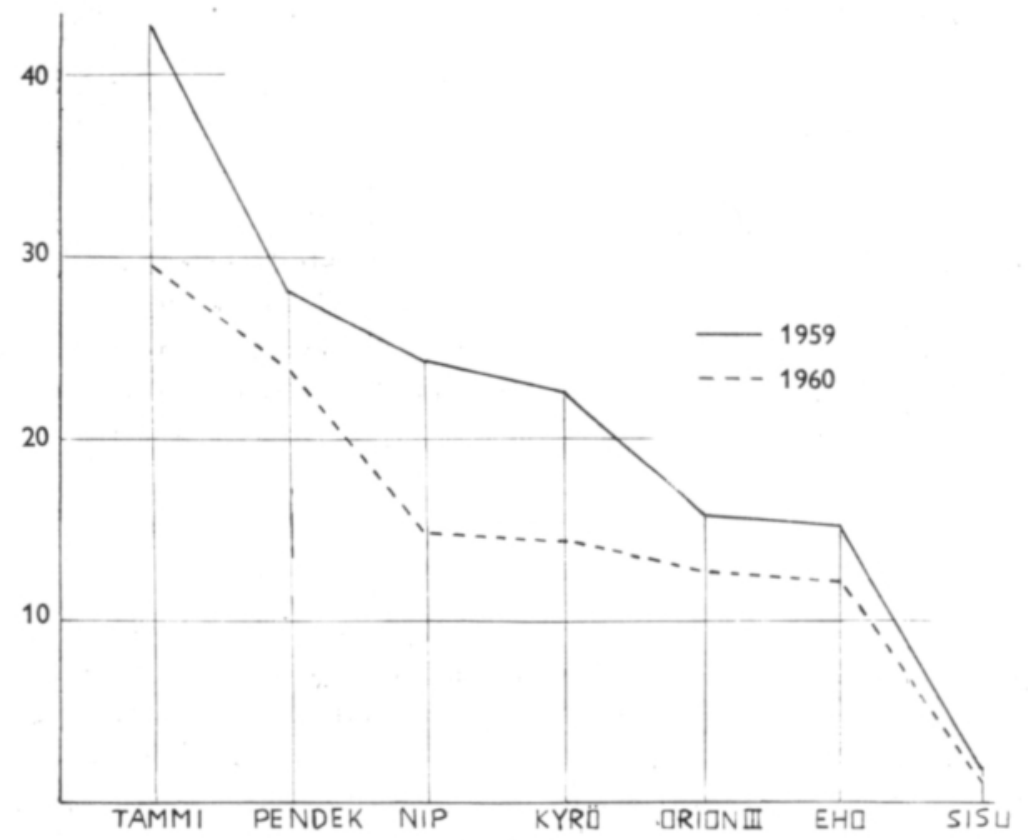

Kuva 3. Sisäkkäisjyviä keskim. kpl/100 g eri kauralajikkeiden siemenerissä vv. 1959 ja 1960. 
huomattavan korkeat. Seuraavalla sijalla olivat Orion III- ja Ehokaurat. Niillä ei sisäkkäisjyvien määrissä eri vuosina ollut yhtä huomattavaa eroa kuin Nipillä ja Kyröllä. Orion III-kauralla oli kaksosten osuus sisäkkäisjyvistä v. 1960 oleellisesti suurempi kuin edellisenä vuonna. Muista tutkituista lajikkeista poikkeaa selvästi Sisukaura, jossa sisäkkäisjyviä kumpanakin vuonna oli hyvin vähän, v. 1959 keskim. $2.1 \mathrm{kpl} / 100 \mathrm{~g}$ ja v. 1960 keskim. $1.3 \mathrm{kpl} / 100 \mathrm{~g}$. Maksimimääräkin oli vain $8 \mathrm{kpl} / 100 \mathrm{~g}$.

Helpeellisten jyvien määrä näissä $100 \mathrm{~g}: n$ kauranäytteissä vaihteli lajikkeesta ja siemenerästä riippuen v. 1959 n. $2700-3000$ ja v. 1960, jolloin 1000 -siemenen paino oli korkeampi kuin edellisenä vuonna, n. $2500-2800$.

\section{Sisäkkäisjyviin sisältyvä roskamäärä}

Lajitellussa siemenkaurassa on yleensä hyvin vähän roskaa, koska kauran lajiperäiset roskat, irralliset kaleet ja tyhjät helpeet ovat kevyitä, ja ne voidaan helposti poistaa. Osa tyhjistä helpeistä on kuitenkin kiinni sisäkkäisjyvissä, joita hyvälläkään lajittelijalla ei voida täydellisesti erottaa. Toisaalta kaikkiin sisäkkäisjyviin ei lainkaan sisälly tyhjiä helpeitä, joten sisäkkäisjyvien määrä ei yksistään aina osoita niiden sisältämää roskamäärää.

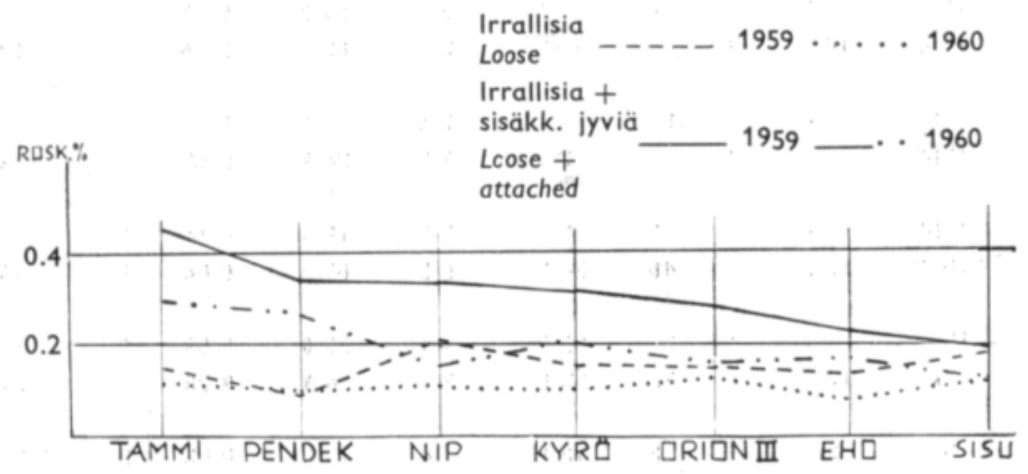

Kuva 4. Irrallinen ja sisäkkäisjyviin sisältyvă keskim. roskamäärä (\%) eri kauralajikkeiden siemen erissä vv. 1959 ja 1960.

Fig. 4. Average percentages of loose inert matter and inert matter attached to the double grain in the seed lots of different oats varieties in 1959 and 1960.

Tässä tutkimuksessa määritettiin rinnakkain näytteiden sisältämät irralliset roskat sekä sisäkkäisjyvissä kiinni olevat roskat (taulukko, kuva 4). Irrallisia roskia oli v. 1959 sadossa vähän enemmän kuin v. 1960 sadossa, mutta eri lajikkeiden välillä ei tässä ilmennyt eroja. Tammikauralla, jolla sisäkkäisjyvien määrä on suuri ja niissä tyhjiä helpeitä paljon, oli sisäkkäisjyvissä kiinni olevia roskia v. 1959 keskim. $0.30 \%$ ja irrallisia roskia keskim. $0.15 \%$ näytteen painosta. Vastaavat luvut v. 1960 olivat $0.18 \%$ ja $0.12 \%$. Myös Pendekillä oli sisäkkäisjyvissä kiinni olevia roskia molempina vuosina enemmän kuin irrallisia roskia, Kyrö, Orion III-, Nipja Ehokauroilla sisäkkäisjyvii n sisältyvä keskimääräinen roskamäärä v. 1959 vaih- 
Taulukko. Sisäkkäisjyvät ja niihin sisältyvä sekä irrallinen roskamäärä $(\%)$ eri kauralajikkeiden siemenerissä vv. 1959 ja 1960

Table. Double grains and inert matter attached to them, and loose inert matter in the seed lots of different oats varieties in 1959 and 1960

\begin{tabular}{|c|c|c|c|c|c|c|c|c|c|c|}
\hline \multirow{3}{*}{$\begin{array}{l}\text { Lajike } \\
\text { Variety }\end{array}$} & \multirow{3}{*}{$\begin{array}{l}\text { Sato- } \\
\text { vuosi } \\
\text { Yield- } \\
\text { year }\end{array}$} & \multirow{2}{*}{\multicolumn{2}{|c|}{$\begin{array}{c}\text { Sisäkkäisjyviä } \\
\mathrm{kpl} / 100 \mathrm{~g} \\
\text { Double grains } / 100 \mathrm{~g}\end{array}$}} & \multirow{2}{*}{\multicolumn{3}{|c|}{$\begin{array}{l}\text { Eri tyyppisiä sisäkkäis- } \\
\text { jyviä keskim. \% } \\
\text { Different types of double } \\
\text { grains, average } \%\end{array}$}} & \multicolumn{4}{|c|}{$\begin{array}{c}\text { Roskia \% (100 g:ssa) } \\
\text { Inert matter \% (in } 100 \mathrm{~g})\end{array}$} \\
\hline & & & & & & & \multicolumn{4}{|c|}{$\begin{array}{c}\text { Sisäkkäisjyvissä kiinni Irallisia } \\
\text { Attached to double } \\
\text { grains }\end{array}$} \\
\hline & & $\begin{array}{l}\text { Keskim. } \\
\text { Average }\end{array}$ & $\begin{array}{l}\text { Vaihtelu } \\
\text { Variation }\end{array}$ & $\begin{array}{c}\text { Tyhjiä } \\
\text { ulkojyv. } \\
\text { Empty } \\
\text { lower } \\
\text { florets }\end{array}$ & $\begin{array}{l}\text { Tyhjiä } \\
\text { sisäjyv. } \\
\text { Empty } \\
\text { upper } \\
\text { florets }\end{array}$ & $\begin{array}{c}\text { Kak- } \\
\text { sosia } \\
\text { Two } \\
\text { grains }\end{array}$ & $\begin{array}{l}\text { Keskim. } \\
\text { Average }\end{array}$ & & $\begin{array}{l}\text { aihtelu } \\
\text { ariation }\end{array}$ & $\begin{array}{l}\text { Keskim. } \\
\text { Average }\end{array}$ \\
\hline Tammi & 1959 & 42.5 & $4-145$ & 68.2 & 7.0 & 24.8 & 0.30 & 0.0 & $3-1.00$ & 0.15 \\
\hline , & 1960 & 29.4 & $4-79$ & 64.5 & 6.3 & 29.2 & 0.18 & 0.0 & $92-0.51$ & 0.12 \\
\hline Pendek & 1959 & 28.1 & $0-106$ & 80.4 & 5.6 & 14.0 & 0.24 & & -0.80 & 0.10 \\
\hline , & 1960 & 23.9 & $1-59$ & 76.5 & 5.8 & 17.7 & 0.16 & 0.0 & $2-0.44$ & 0.11 \\
\hline Nip & 1959 & 24.2 & $1-64$ & 45.3 & 3.7 & 51.0 & 0.13 & 0 & -0.39 & 0.21 \\
\hline , & 1960 & 14.7 & $5-48$ & 35.2 & 2.7 & 62.1 & 0.05 & 0 & -0.24 & 0.11 \\
\hline Kyrö & 1959 & 22.4 & $1-121$ & 65.8 & 2.4 & 31.8 & 0.16 & 0.0 & $1-0.95$ & 0.16 \\
\hline , & 1960 & 14.4 & $0-67$ & 72.1 & 3.0 & 24.9 & 0.10 & 0 & -0.63 & 0.10 \\
\hline Orion III & 1959 & 15.6 & $1-59$ & 80.1 & 0.3 & 19.6 & 0.14 & 0.0 & $91-0.61$ & 0.15 \\
\hline , & 1960 & 12.6 & $1-46$ & 34.2 & 5.0 & 60.8 & 0.04 & 0 & -0.13 & 0.13 \\
\hline Eho & 1959 & 15.1 & $0-81$ & 53.3 & 7.1 & 39.6 & 0.09 & 0 & -0.64 & 0.14 \\
\hline , & 1960 & 12.1 & $1-36$ & 72.6 & 3.1 & 24.3 & 0.08 & 0 & -0.27 & 0.09 \\
\hline Sisu & 1959 & 2.1 & $0-8$ & 78.6 & 3.4 & 18.0 & 0.02 & 0 & -0.08 & 0.18 \\
\hline • & 1960 & 1.3 & $0-7$ & 69.6 & 2.9 & 27.5 & 0.01 & 0 & -0.07 & 0.12 \\
\hline
\end{tabular}

(Kaikista lajikkeista tutkittu kumpanakin vuonna 55 näytettä)

(55 samples of every variety were tested each year)

teli $0.16-0.09 \%$ ja oli sama tai pienempi kuin irrallisten roskien määrä. Seuraavana vuonna erikoisesti Nip- ja Orion III-kauroilla sisäkkäisjyvissä kiinni oleva roskamäärä oli pieni, koska niillä kaksosten osuus sisäkkäisjyvistä oli hyvin suuri. Sisulla on sisäkkäisjyviä niin vähän, että niiden sisältämä roskamäärä on merkityksetön siementavaran puhtautta arvosteltaessa.

Keskiarvojen valossa sisäkkäisjyvien sisältämä roskamäärä on siis suhteellisen pieni niilläkin lajikkeilla, joilla sisäkkäisjyviä on paljon. Mutta yksityisten siemenerien kohdalla saattaa se useilla lajikkeilla, mutta erityisesti Tammi- ja Pendekkauroilla olla merkityksellinen. Tähän aineistoon sisältyi esim. sellainen Tammi- 
kaura, jossa sisäkkäisjyvissä kiinni olevia roskia oli $1.00 \%$ siitä huolimatta, että erä oli hyvin puhdistettu, koska irrallisia roskia oli vain $0.06 \%$. Onpa siementarkastuslaitoksessa tavattu sellaisiakin Tammikaura-näytteitä, joissa sisäkkäisjyviin sisältyviä tyhjiä helpeitä on ollut jopa $2 \%$ näytteen painosta.

\section{Tulosten tarkastelua}

Kirjallisuudessa $(2,3)$ esitettyjen tietojen mukaan sisäkkäisjyvien kehittyminen johtuu osittain perinnöllisistä tekijöistä, mutta siihen vaikuttavat huomattavasti myös ulkonaiset olosuhteet. Tämän kahta satovuotta koskevan, lajitellulla siemenviljalla suoritetun tutkimuksen perusteella voitanee päätellä, että tutkituilla kauralajikkeilla on erilainen perinnöllinen taipumus sisäkkäisjyvien muodostumiseen. Suurin se on Tammikauralla; sitten seuraavat järjestyksessä Pendek, Nip, Kyrö, Orion III, Eho ja Sisu. Sisäkkäisjyvien määrä kaikilla lajikkeilla oli v. 1959 suurempi kuin v. 1960, mikä osoittaa, että eri vuosien sadot ovat tässä suhteessa erilaisia. Sisäkkäisjyvien runsauteen v. 1959 sadossa lienee vaikuttanut kasvukauden poikkeuksellinen kuivuus, sillä kuivuuden on havaittu edistävän sisäkkäisjyvien samoinkuin yleensä tyhjien jyvien kehittymistä (3). Myös suuret vaihtelut sisäkkäisjyvien määrissä samaa lajiketta olevien, erilaisissa olosuhteissa kasvaneiden siemenerien välillä osoittavat ulkonaisten tekijäin suurta vaikutusta sisäkkäisjyvien kehittymiseen.

Tutkimus osoittaa myös, että huomattava osa kauran kauppasiemenessä olevasta roskasta on kiinni sisäkkäisjyvissä. Näin on laita erikoisesti Tammi- ja Pendekkauroilla, mutta muissakin lajikkeissa on yksityisiä siemeneriä, joissa sisäkkäisjyvissä kiinni olevien tyhjien helpeiden määrä on monta kertaa irrallisten roskien määrää suurempi. Jos kauran puhtausmäärityksessä sisäkkäisjyvät sellaisinaan katsotaan puhtaiksi siemeniksi, kuten nykyään tehdään, jää kauraan piilevää roskaa. Keskiarvolukujen valossa tämä piilevä, sinänsä vaaraton roskamäärä on kuitenkin painoltaan suhteellisen pieni niilläkin lajikkeilla, joilla sisäkkäisjyviä on runsaasti. Yksityisissä siemenerissä ja erityisesti sellaisina vuosina, jolloin sisäkkäisjyviä on paljon, se kuitenkin saattaa nousta niin suureksi, että sillä on käytännöllistäkin merkitystä siemenerän puhtautta arvosteltaessa. Koska kuitenkin sisäkkäisjyvien irrottaminen tai niiden poistaminen käytännössä lajittelemalla on erittäin vaikeaa, osittain mahdotontakin, on tältä kannalta tarkoituksenmukaisempaa myös siementavaran puhtauden määrittämisessä arvostella sisäkkäisjyvät yksikkönä eikä erillisinä jyvinä.

\section{Yhteenveto}

Seitsemän siemenkaupassa yleisimmän kauralajikkeen sisäkkäisjyvien määrää ja niiden vaikutusta siementavaran puhtauteen tutkittiin käyttämällä aineistona viralliseen siementarkastukseen lähetettyjä näytteitä sekä v. 1959 että v. 1960 sadosta.

Tutkituilla lajikkeilla osoittautui olevan erilainen taipumus muodostaa sisäkkäisjyviä. Suurin se oli Tammikauralla; sitten seurasivat järjestyksessä Pendek, Nip, Kyrö, Orion III, Eho ja Sisu, jolla sisäkkäisjyvät olivat harvinaisia. 
Sisäkkäisjyvien määrä eri vuosien sadoissa oli erilainen. Erityisen kuivana vuonna 1959 se oli suurempi kuin vuonna 1960. Myös saman lajikkeen erilaisissa olosuhteissa kasvaneissa siemenerissä sisäkkäisjyvien määrä vaihteli paljon.

Sisäkkäisjyviin sisältyvien tyhjien helpeiden, roskien, määrä oli painoltaan keskimäärin suhteellisen pieni niilläkin lajikkeilla, joilla sisäkkäisjyviä oli paljon. Yksityisissä siemenerissä se kuitenkin voi nousta niin suureksi, että sillä on käytännöllistäkin merkitystä siemenerän puhtautta arvosteltaessa.

\title{
KIR J A L L IS U U T T A
}

(1) Heinisch, Otтokar 1955. Das landwirtschaftliche Saatgut. Leipzig.

(2) Hunter, Herbert 1924. Oats: Their varieties and characteristics. London.

(3) Zade, Adolf 1918. Der Hafer. Jena.

\section{S U M M A R Y:}

DOUBLE GRAINS OF DIFFERENT OATS VARIETIES AND THEIR INFLUENCE UPON THE PURITY OF SEED

MERI JOKELA

\author{
State Seed Testing Station, Helsinki
}

This study of double grains included all oats varieties at present common in the seed trade in Finland. The material consisted of seed samples sent to the State Seed Testing Station for official testing and covered the years 1959 and 1960 . The vegetation period 1959 was exceptionally dry in Finland.

The results of the study are presented in the Table.

The number of double grains in the seed lots of each variety was greater in the yield of 1959 than in that of 1960, but the relative order of the varieties was the same in each year. The number of double grains was highest in the seed lots of the variety Tammi and lowest in the seed lots of the variety Sisu, in which the double grains were relatively uncommon. Variation between the different samples of the same variety was great.

The quantity of sterile florets attached to the double grains was on an average relatively small in weight even in the seed lots of the varieties with a great number of double grains. But in some seed lots, especially of the varieties Tammi and Pendek, the weight of the sterile florets was great enough to be of practical value in judging the purity of seed. 